\title{
Studying Media: A Conversation with Jussi Parikka
}

Yigit Soncul and Jussi Parikka

It is a tricky task to introduce Jussi Parikka due to the breadth of his scholarly activities. The Finnish professor has been a prolific figure in media theory over the past decade and his work on materialities and temporalities of media, anomalies in digital culture and media ecologies have catalysed many critical looks on the present technological situation and political economy. He is the editor and author of numerous books, including the Anne Friedberg Award for Innovative Scholarship winner Insect Media (2010) and recently published $A$ Geology of Media (2015). Parikka has also contributed to the emergence of the field, "Media Archeology" with his books, Media Archaeology (2011) coedited with Erkki Huhtamo and monograph What is Media Archaeology? (2012). He is currently working at Winchester School of Art, University of Southampton as Professor in Technological Culture and Aesthetics, and University of Turku as Adjunct Professor in Digital Culture Theory.

In the second issue of Diegesis Journal we aim to continue problematising the study of audiovisual media in both institutional and national levels. Our very initiation was symptomatic of a renewed emphasis on theory in Istanbul Bilgi University, Film and Television Department - which from a traditional Anglo-American perspective is more a film school than a film studies department: a prevalent ratio of practice to theory in undergraduate Media and Communications programmes in Turkey. In what follows, Parikka joins us to discuss the present and speculate on alternative futures. 
Yigit Soncul: In media and communications departments across universities in Turkey theory seems to be given a supplementary role in the education of undergraduates who are assumed to become producers of content. Since the goal is to build an elementary theory literacy to make the students competent practitioners, there is little utilisation of theoretical frameworks which would focus on anything outside the borders of the screen. As an academic with positions both in the UK and Finland, and as a theorist who rarely prioritises the phenomenological, can you comment on other ways of studying media which may offer possible futures for our case?

Jussi Parikka: It's a question that perhaps pertains to Turkey and it is also something that definitely runs through academic departments more globally too: a resistance to theory, a celebration of the entrepreneur, the vocational, the narrow definition of useful. To start with your question, a lot of grounding of media studies was always very focused on media as content; semiotic analysis, formal discourse analysis and many other qualitative methods alongside quantitative methods. A lot of them were either centred on language - even the image as language, as we learned in certain versions of film theoryand the world as composed as play of meanings, representations, etc.

I myself have been interested and written about what could be pitched as new media studies - not merely studies of new media, but new theories and methods of media studies that have emerged in the past 10-20 years after the first waves of theory that came from cultural studies and other directions. Media archaeology is one such field, stemming 
as part of cultural history of media and technology, German media theory and also the legacy of Marshall McLuhan, Harold Innis and the so-called Canadian media theory. Media archaeology has been defined by writers such as Erkki Huhtamo, Siegfried Zielinski and others as a field interested in the outside of the mainstream stories, apparatuses, discourses and materialities of media which are important ways to remind against the hegemony of "new" and against the supposition of progress. The likes of Friedrich Kittler did major work in vitalizing media theory as a materially focused field that investigated the historical conditions of media - and media technologies as conditions of history. History was not detached from theoretical work, but become tightly interwoven into a peculiar style of building arguments. There would be a lot to be said about Kittler and other exciting theorists of media. In What is Media Archaeology? I tried to evaluate some of this in the context of new film studies and for example software studies.

Of course I am not merely interested in what media archaeology could offer to the Turkish field of film, media and cultural theory but also how media archaeology can be expanded and changed with the legacies and traditions of technology and science that one can excavate in the region, the Islamic traditions and broadly speaking the Middle-East. For example Ayhan Ayteş has recently done work towards this direction but connecting the historical legacy of automata to even current cognitive sciences and cognitive capitalism. 


\section{Do you think software studies secured a central position lately? What are the} effects of it on media research in general?

Indeed, software studies and platform studies are fields that are relative newcomers in media research. Besides introducing new topics that relate to digital culture, I would say that they have forced an implicit institutional or pedagogical change too. Software studies has been at the forefront of the question: should we even in humanities and social sciences learn not only natural languages but also programming languages? Like Kittler much earlier polemicised: contemporary humanities demands that you master not only key human languages but also how to program.

No wonder that fields such as Digital Humanities are gaining ground, even if some of that discourse has forgotten that some fields in media studies were early on thinking about the questions how our universities and curricula have to change in the age of computational media. Consider how important media studies has been and also the media arts after World War II presenting practical interventions into media-making.

Furthermore, to continue the list relating to new media studies, I have found the work in media ecology and for example new materialist theory important and challenging the method of representational analysis with themes that relate to embodiment, the nonhuman and the deep interconnectedness of cultural processes with aesthetic and technological agendas. In short, media studies has been positively forced to question how it relates and differs from critical studies of technology. All of this is to the positive and bene- 
fits the field. Also in film and television studies, where media ecology (both with McLuhan and in Matthew Fuller's work), and for example media archaeology constantly ask: what are the multiple and complex relations of new media and old media; is remediation the key term to understand media change? How can media archaeology open up complementary ways of excavating the other stories of media culture, as a way to excavate the old in the new, and the new in the old to use Zielinski's words.

To return to the beginning, and the question about theory: I think it's a broader trend to steer away from theory. Academic degrees are increasingly pitched as glorified job training; learning a skill, vocationally important skills. There's a political economy behind these choices too. Universities have been forced to adopt this tightly vocational agenda and have too easily played along the entrepreneur discourse; lusting after a Stanford-model, too many universities globally want to pitch themselves as places where students work primarily towards patents, inventions and becoming entrepreneurs. Nothing wrong with that, except if it becomes the single-minded focus of universities where senior managers earn their $\mathrm{CV}$-points by external money income, patent statistics, etc. And other universities, the ones that don't even pretend to do research, promise to prospective students a career in creative industries where mastering the use of video camera, software editing skills and interpersonal communication skills for job interviews is seen as adequate "media degree". Again, nothing wrong with that except that we need to defend theory as part of the wider role of media studies as one of the key theoretical fields that can make sense of contemporary culture.

We need to be able to demonstrate that theory is not just generic meditation of the world, or useless skills in analysis; it is a mode of being in the world, and active way of 
being able to problematize. Theory is a practice too and relates funnily enough to such skills that according to many polls employers value: inventiveness, adaptability, problemsolving, and learning. The most innovative programs and degrees emerging are ones with a combination of theoretically innovative ideas and readings, and modules where you can develop your creative skills. Of course, Turkey has a lot of potential here too, with the great skills in design that one comes across on a regular basis.

Indeed, theory must be defended. One of the most crucial subjects today seems to be the environmental catastrophe we are facing and your recent work relating to the topic, I think, offers an apt example on how theory can directly engage with the problems of the present. Could you elaborate on how The Anthrobscene and the recently published $A$ Geology of Media problematise the unsustainability of our media condition?

On a continuous basis, tons and tons of media fall out of use, undermining the fallacy that media is for use; that media usage and users is the only focus for analysis becomes soon overshadowed by how massively larger question that of disuse is. Media technological devices have an afterlife as trash - sometimes as a secondary mine of metals - both expressing the logic of global capitalism; media travel routes across the globe pending on where its usage is, but also that it travels to places where it gets dismantled with unfortunate risks to health and the environment. Modern media is, after all, toxic. This perspective inspired me to write about electronic waste, and to expand that topic into the geology of media-project. 
In this case, I approach the materiality of media through a much more distributed level than that of the hardware. You know all those accusations that focusing on media devices risks being technologically determinist? Well, the issue is that we are not consistently enough focusing on them; media materiality consists of the metals, materials, energy that through its global production and waste defines a level of social and planetary forces in need of urgent attention. There is a materiality harder than harder and that takes us to discussions about the earth, the planetary.

Media design should turn its attention to these issues of unsustainability and more intensively focus on how to design products that resist planned obsolescence and promote much fairer material production chains that should also aim to sustain a computational culture of environmental dimensions; I avoid the term "sustainability" often because the political economic situation should not be sustained, which is too often the aim of the green initiatives that fail short. Instead, we need ecological thinking that thinks across the environment, design and political economy.

The Anthrobscene is a short preview "single of the longer book", A Geology of Media. That book is itself the third and final part of my media ecology-trilogy that started with viruses in Digital Contagions, continued with Insect Media and now expands to discuss how contemporary media culture and media arts has geological materialities at its centre. 
Let us readdress the situation in the first question from another angle: What is the relevance of theory to creative practitioners and especially to those who operate in audiovisual media? Does theory open up ways in which creative practitioners may participate in the process of subversion of the structures of power their works are being mediated through?

Theory is itself a practice too - but yes, I get your question and how we need to think across any binary divisions between theory vs. practice. This is imperative and we need theoretically aware practitioners as much as theorists who actually know how things work; how technologies work; how media functions on the ground level, whether it is software, the internet down to its protocols, etc. The increasing focus on mastering software packages to produce creative industries content should be challenged by a hacker mentality of wanting to pick things apart and consider also what your own practice is doing and not doing; to become a self-reflective practitioner who understands design as part of cascading effects. This is where the true critique of power lies: in the ability to design alternative systems, or perhaps more tactically, to understand from what sort of components, whether visual or for example software, systems of power, infrastructure, is composed of.

Theoretical ideas and frameworks are tools that also can have cascading effects. Theory triggers ways of seeing in the world and can be continued by other means; design, art, audiovisual media. If like with Rancière we approach issues of politics and the aesthetic as a problem of how modes of perception are allocated in the world, the way to subvert is to allocate alternatively; an education of the senses by way of concrete "seeing 
differently". A true audiovisual pedagogy or even manipulation, a sort of evil media stance that Matthew Fuller and Andrew Goffey proposed in their work over the past years.

On an institutional level, our work at Winchester School of Art has tried to address such ideas and practices. I've been lucky to participate as a theorist to some of the design and fine art projects from undergraduates to graduate students, and in general, also on research level we try to keep both sides tightly connected. The aim is to create such an institutional context where practice-based research ties up with theoretical work.

\section{I am also thinking about your work with Garnet Hertz, Zombie Media: Cir- cuit Bending Media Archaeology into an Art Method, where you propose revitalisa- tion of discarded media. What are the possibilities such stance evokes?}

We use the idea of zombie media to develop a more active position to dead media. In short, if dead media refers to the various technologies and inventions and ideas that have fallen out of use - whether the rotary dial telephone or the fax machine or some other of the hundreds of inventions of past decades - our take on zombie media investigates the afterlife of such seemingly dead technologies; on the one hand, the issues of electronic waste from the discarded electronic technologies and on the other, the possibilities of reappropriation and redesign of obsolete devices by way of circuit bending and hardware hacking. Garnet is a critical designer, artist and scholar and our collaboration took form of both writing (the Zombie Media-text) and workshops where Garnet led a crash course into circuit bending old electronic toys. He has been occupied with these 
sorts of activities and other art projects and for me, it allowed a great collaboration that extended the art-theory link into a collaboration that really opened a different way of thinking about media.

Zombie media was also meant as a think-piece about media archaeology; media archaeology not merely as an excavation into the historical examples and archives, but to the contemporary technology that is obsolete. Planned obsolescence is part of this in terms of design - to build things to break - and the issues of design and production of obsolescence becomes part of the media archaeological agenda. The opening up of a device, whether an old radio, a computer or any technological device in fact can become an empowering way of looking inside the black box to try to decipher what is the operational logic that structures our cultural world too.

\section{This final question stems from us being an online publication. Can you} speculate on how surveillance might develop in the post-Snowden era? What should we expect and how can we take action?

Who needs surveillance when we have Facebook? Jokes aside, the key thing is how surveillance has been distributed so that it is not an external situation of observing this or that person but a system completely embedded in normalised social activities. The amount of data we share or agree to be tapped into through social media platforms has enacted a situation, which is not merely of surveillance but penetrates the social fabric. It both allows an easy access for governmental and corporate security agencies to track and predict movement and also itself is such a platform of preemption in several ways. 
Surveillance is becoming more mobile. Technologies of surveilling space are becoming automated (automated facial recognition) and mobile - for example drones. The smart dust of the future is one of massive amounts of distributed agents that receive and transmit sensor data; a cartography enacted by these little proxies of corporate and military agencies.

In other words, when discussing surveillance we need to be aware of both software and hardware developments. What is technologically possible should be benchmark level for any political discussion concerning surveillance; again, one cannot talk about politics without understanding some of the issues of how technological development is linked to this. This is why our field from film studies to media and communications has to be at the forefront of this discussion and continue to develop its theoretical and practical knowledge in relation to such social challenges. 